\title{
The 18-Month Impact of an Emergency Room Intervention for Adolescent Female Suicide Attempters
}

\author{
Mary Jane Rotheram-Borus, John Piacentini, Coleen Cantwell, Thomas R. Belin, and Juwon Song \\ University of California, Los Angeles
}

\begin{abstract}
Following a suicide attempt by female adolescents, the impact of a specialized emergency room (ER) care intervention was evaluated over the subsequent 18 months. Using a quasi-experimental design, this study assigned 140 female adolescent suicide attempters (SA), ages 12-18 years, and their mothers (88\% Hispanic) to receive during their ER visit either: (a) specialized ER care aimed at enhancing adherence to outpatient therapy by providing a soap opera video regarding suicidality, a family therapy session, and staff training; or (b) standard ER care. The adjustment of the SA and their mothers was evaluated over 18 months (follow-up, 92\%) using linear mixed model regression analyses. SA's adjustment improved over time on most mental health indices. Rates of suicide reattempts $(12.4 \%)$ and suicidal reideation $(29.8 \%)$ were lower than anticipated and similar across ER conditions. The specialized ER care condition was associated with significantly lower depression scores by the SA and lower maternal ratings on family cohesion. Significant interactions of intervention condition with the SA's initial level of psychiatric symptomatology indicated that the intervention's impact was greatest on maternal emotional distress and family cohesion among SA who were highly symptomatic. SA's attendance at therapy sessions following the ER visit was significantly associated with only one outcome-family adaptability. Specialized ER interventions may have substantial and sustained impact over time, particularly for the parents of youth with high psychiatric symptomatology.
\end{abstract}

Adolescent suicide attempts are a significant problem, with $7.7 \%$ of high school students reporting attempts and $2.6 \%$ saying their attempt required medical attention (Centers for Disease Control and Prevention [CDC], 1998). Adolescent suicide attempters (SA) are at increased risk for repeat attempts, long-term psychiatric symptoms, and academic, social, and behavioral problems (Shaffer \& Piacentini, 1994). In spite of their great need for mental health intervention, fewer than $50 \%$ of adolescent attempters are referred for psychotherapy following their emergency room (ER) visit (Piacentini et al., 1995; Spirito, Brown, Overholser, \& Fritz, 1989), and a large proportion of these individuals fail to attend their initial treatment session. Of those who do attend, many do not complete treatment (Piacentini et al., 1995; Spirito et al., 1989). Nonattendance to follow-up treatment by suicidal adolescents is especially disturbing, considering that psychiatric intervention can reduce subsequent attempts and social maladjustment (Rotheram-Borus, Piacentini, Miller, Graae, \& Castro-Blanco, 1994; Shaffer \& Piacentini, 1994).

There are many reasons why individuals fail to attend treatment following an ER visit for a suicide attempt. Repetitive evaluations, lengthy waiting periods, bureaucratic registration procedures, and

Mary Jane Rotheram-Borus, John Piacentini, Coleen Cantwell, Thomas R. Belin, and Juwon Song, Department of Psychiatry, University of California, Los Angeles.

This work was supported by National Institute of Mental Health Grants MH48059, MH43878, and MH57082.

Correspondence concerning this article should be addressed to Mary Jane Rotheram-Borus, Department of Psychiatry, Division of Social and Community Psychiatry, University of California, Los Angeles, 10920 Wilshire Boulevard, Suite 350, Los Angeles, California, 90024. Electronic mail may be sent to rotheram@ucla.edu. poor communication in the ER may lead patients to develop negative associations with the health care delivery system (Haynes, 1979; Hazzard, Hutchinson, \& Krawiecki, 1990) and to increase nonadherence. In addition to barriers with providers, the parents' perceptions of the suicidality of their children also appear to be associated with nonadherence. The day after a suicide attempt, families often report "it was a big mistake-nothing was wrong" (Rotheram-Borus et al., 1994).

To address barriers to follow-up outpatient treatment, a specialized ER care program was developed and evaluated with the design summarized in Figure 1 (Rotheram-Borus, Piacentini, Miller, et al., 1996). When the SA and their parents first entered the ER care (either specialized or standard care), the attending physician rated the lethality of the adolescent's suicide attempt (Pierce Suicide Intent Scale; Pierce, 1977) and level of depressive symptomatology (Hamilton Depression Inventory; Hamilton, 1960), conducted a mental status exam on the adolescent, and gathered sociodemographic information from the adolescent and the parents. Families did not differ in terms of demographic characteristics, and SA were very similar on preintervention clinician ratings of characteristics of the attempt, depression, suicidality, and substance use across the two study conditions (specialized and standard care). Using a quasi-experimental design, this study then assigned SA and their parents to receive either the specialized or standard ER care. Assignment was based on time of presentation to the ER. The specialized ER care included staff training, presentation of a videotaped orientation to the family regarding the dangers of ignoring suicide attempts and the potential benefits of treatment, and delivery of a structured family therapy session while the SA and their mothers were in the ER. The specialized ER care was designed to frame or define the suicide attempt to the SA and their families as (a) an ineffective 


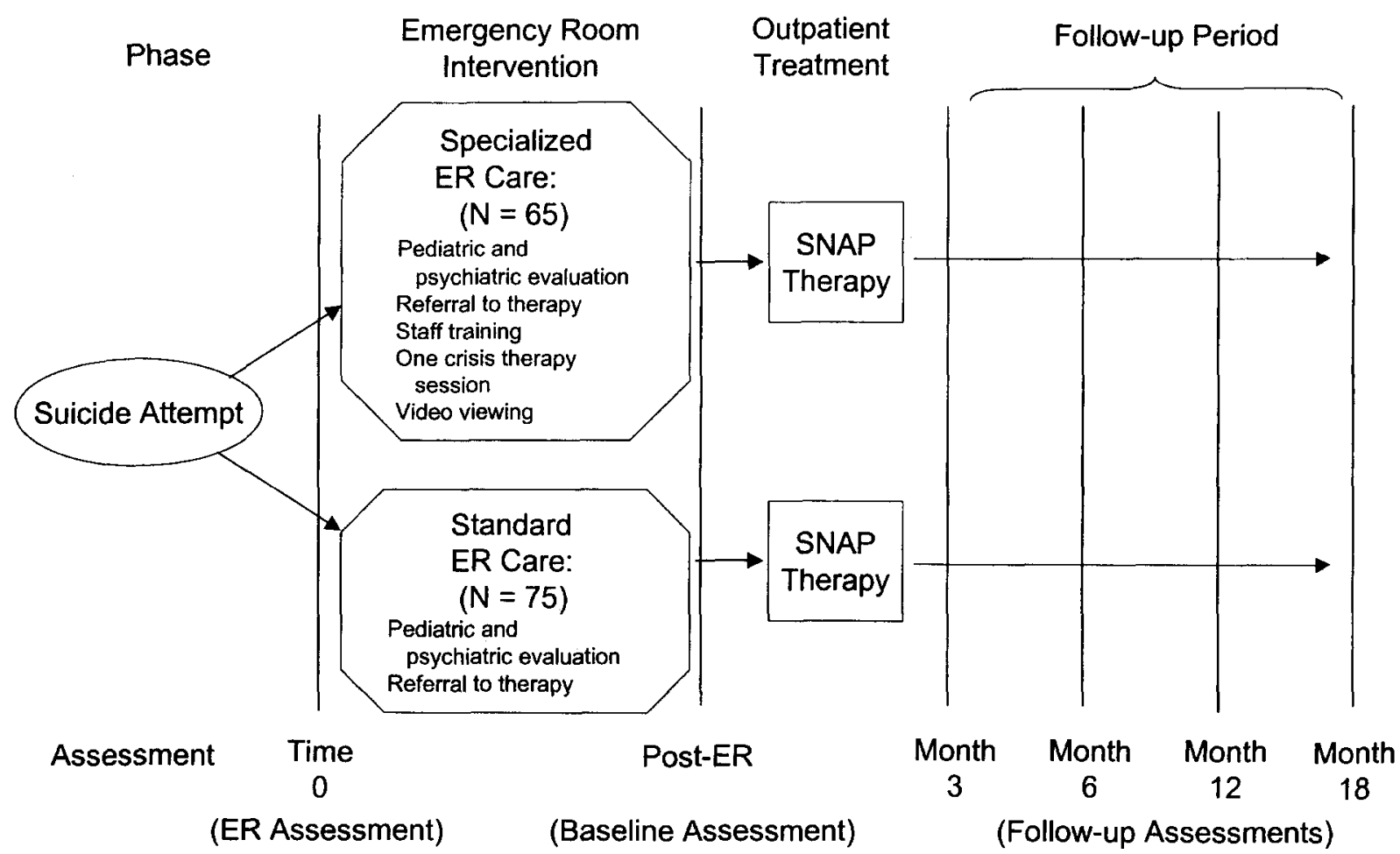

Figure 1. Design of the emergency room study.

problem-solving strategy; (b) a critical event requiring immediate therapeutic intervention to prevent its likely reoccurrence; (c) a roadblock to the positive, loving feelings shared by the SA and their parents; and (d) a problem that could be addressed in six sessions of therapeutic intervention. Parents were asked to endorse attendance for themselves and their child at Successful Negotiation Acting Positively (SNAP), a six-session outpatient program that was designed to be interesting and rewarding.

Following the ER car, SA in the specialized ER care condition were significantly less depressed and reported less suicidal ideation after receipt of this intervention than SA receiving standard ER care. Similarly, mothers receiving specialized ER care were significantly less depressed at the baseline (post-ER) assessment and reported less emotional distress and more positive attitudes toward treatment than mothers in the standard ER care condition (Rotheram-Borus, Piacentini, Van Rossem, et al., 1996). Thus, the effects of the specialized ER care were immediately observable in the baseline interviews.

The baseline assessment was conducted shortly after the ER care and, then the SNAP therapy was delivered. Among the Hispanic adolescent female SA, the specialized ER care then increased adherence to the SNAP therapeutic intervention over the next 6 months compared with the standard ER care condition (Rotheram-Borus, Piacentini, Van Rossem, et al., 1996).

In this report, we examine whether the specialized ER care continued to have a positive impact on adolescent and maternal symptoms over 18 months, compared with youths receiving standard ER care. The specialized ER care program, designed to reduce suicide reattempts and to increase adherence to a therapeutic intervention (i.e., SNAP therapy), targeted both the SA and their parents. We anticipated fewer suicide reattempts among the
SA in the specialized ER care condition compared with those in the standard care condition. We also hypothesized that SA and parents who received the specialized ER care would demonstrate fewer symptoms of emotional distress and more positive perceptions of their family relationships compared to SA and parents in the standard ER care condition. Because the outpatient SNAP therapy was standardized, multivariate analysis allowed us to examine simultaneously the effects of the specialized ER care and SNAP.

The literature on SA suggests that there are multiple subgroups of attempters (Shaffer \& Piacentini, 1994), so we did not expect the effects of the specialized ER care to be uniform across subgroups of SA. In particular, we anticipated the program's impact to vary depending on the SA's degree of psychiatric symptomatology at the time of the suicide attempt. Earlier treatment outcome studies have noted that the most seriously disturbed youths are the least likely to improve in response to treatment (Bickman, 1996). In a study by Pfeffer and colleagues (1994), hospitalized SA treated with antidepressant medication for longer periods of time were 17 times more likely to make a suicide attempt over the next 6 to 8 years than those receiving less antidepressant treatment. Adolescents with major psychiatric disorders may have mental health problems over their lifetime that are difficult to change and unlikely to improve, even if substantial treatment is received. Therefore, the specialized ER care was hypothesized to have the least impact on the most psychiatrically distressed SA and mothers; we anticipated that their symptoms would persist over time regardless of treatment. In contrast, youths who attempt suicide, but who have little symptomatology in their day-to-day lives, are the most likely to improve, even if little or no treatment is received. Therefore, among the SA with low symptomatology, we 
theorized that those receiving specialized or standard ER care might have similar results because the SA and their mothers would both recover quickly from the event.

Between these extremes, suicide attempts arising in response to transitory stressors, family problems, or stressful life events (see Shaffer \& Piacentini, 1994, for a review) are more likely to occur in SA with moderate psychiatric symptomatology. These youth have poor skills to cope with these stressors; therefore, interventions may increase the coping and behavioral skills of these youth. Similarly, the mothers of SA would not perceive their children's status as either chronic and unchangeable or currently healthy; these mothers were anticipated to have the greatest optimism and improvement following the specialized ER care program. Given that the moderately symptomatic SA were expected to have the greatest responsiveness to the intervention, we examined the efficacy of the specialized ER care over 18 months as a function of SA's initial levels of psychiatric symptomatology. The level of symptomatology was highly skewed; in order to reduce the possibility of a few scores unduly influencing the interpretation of the outcome and to allow us to examine nonlinear trends in a relatively small sample, SA were categorized on the basis of their psychiatric symptomatology. Therefore, SA were classified immediately after their suicide attempt as having low, moderate, or high symptomatology according to the number of symptoms they endorsed on the Diagnostic Interview Schedule for Children (Shaffer et al., 1996). Although it would have been possible to examine both linear and quadratic effects of the SA's initial level of symptomatology on adjustment over time, our three-level categorization allows for nonlinear effects in a framework that is straightforward to interpret.

\section{Method}

\section{Participants}

The eligibility criteria for the SA were: admitted for a suicide attempt to the ER (i.e., had inflicted physical harm to self with a desire to die), aged 12-18 years old, not psychiatrically hospitalized for more than 1 week, female, and not referred to hospitals outside of the New York City area. The ER at Columbia Presbyterian Medical Center, New York admitted 468 suicidal youths from March 1991 to February 1994: $18.6 \%(n=87)$ were male; $26.5 \%(n=124)$ were females identified only as suicidal ideators; $8.8 \%(n=41)$ were females who were admitted for more than 1 week to a psychiatric ward following the suicide attempt and were unavailable for treatment; 5\% ( $n=24)$ were ineligible due to low IQ, wrong age, no parent or family, or having moved immediately out of the area; and $5 \%(n=25)$ were referred to treatment programs closer to their residence. This yielded 167 eligible participants of whom 150 were successfully recruited: Nine were released from the ER before the recruiter could approach them and successfully schedule a follow-up appointment, and eight refused to participate. The number of refusals was too small to examine significant differences between this subgroup and the final sample; however, based on the attending physicians' ratings in the ER, the SA who refused appeared similar in sociodemographic profile and had similar events precipitate the suicide attempt. Among the $150 \mathrm{SA}$ recruited, with informed consent of the $\mathrm{SA}$ and their primary caretakers, $10 \mathrm{SA}$ did not complete the baseline assessment, leaving 140 available for the present analysis.

\section{Procedures}

As outlined in Figure 1, shortly after the SA and their mothers arrived in the ER, the attending physician completed a brief demographic assessment of the SA and their parents, and then assessed the SA using the Hamilton Depression Inventory (Hamilton, 1960), the Pierce Suicide Intent Scale (Pierce, 1977), and a mental status exam (Time 0). Following administra- tion of these measures, the SA and their parents received either standard ER care or specialized ER care. It was not possible to randomize individual SA to intervention conditions because the environment and many persons in the ER were targeted by the specialized ER care. Previous research demonstrated post-ER differences between the families receiving specialized and standard ER care, with those SA and mothers receiving the specialized ER care demonstrating lower levels of depression, and mothers demonstrating more positive attitudes toward treatment (Rotheram-Borus, Piacentini, Van Rossem, et al., 1996). In the month following discharge from the ER, the SA and their mothers were administered (typically in their home) a comprehensive psychiatric and psychosocial assessment battery (post-ER assessment). Across conditions, the SA and their mothers then entered outpatient treatment, SNAP, in which the number of treatment sessions were monitored.

Standard ER care. The standard ER care procedures (from March 1991 to August 1992; $n=75$ ) included evaluations by a pediatrician and a child psychiatry fellow or adult psychiatric resident to determine whether the suicide attempt was serious enough for either medical or psychiatric hospitalization, and to prescribe appropriate medical procedures to be administered (e.g., gastric lavage). The SA and their mothers received a referral to the SNAP outpatient therapy.

Specialized ER care. The specialized ER care program (from September 1992 to February $1994 ; n=65$ ) introduced three changes to the standard ER care procedures (Rotheram-Borus, Piacentini, Van Rossem, et al., 1996). First, six groups of primary ER staff (child psychiatry fellows, adult psychiatry residents, pediatricians, nurses, security guards, and admitting clerks) were trained in separate 2-hr sessions according to a detailed training manual. The goals of these trainings were to teach ER staff how to enhance positive patient interactions, reinforce the importance of outpatient treatment, and recognize the seriousness of suicide attempts (Miller, Rotheram-Borus, Piacentini, \& Graae, 1992). Trainings were repeated over time to ensure training for all new staff and medical trainees rotating to the ER. Second, a 20-min "soap opera" videotape was shown to all SA and their mothers in the ER to instill realistic expectations regarding treatment. Spanish-speaking families viewed the video in Spanish. The video reviewed the stories of two SA, one of whom had repeated her suicide attempt after not following up on outpatient treatment. Third, a bilingual crisis therapist met with the SA and their mothers in the ER to screen and discuss the videotape, conduct a therapy session, and contract for follow-up outpatient treatment. In the therapy session in the ER, the therapist conducted a behavioral assessment of behavioral risk for imminent danger of suicide (Rotheram-Borus, 1987), asked the SA and the mothers to identify positive attributes of themselves and their family, and made a plan for the SA on coping with future suicidal feelings. This strategy for assessing imminent danger of suicide was repeated weekly in the SNAP therapy.

SNAP: follow-up outpatient therapy. The amount of follow-up outpatient therapy received was systematically monitored following discharge from the ER. The treatment was standardized across intervention condition and consisted of a six-session, highly structured treatment protocol (SNAP; Miller, Rotheram-Borus, Piacentini, Graae, \& Castro-Blanco, 1992), developed specifically for SA and their families (Rotheram-Borus et al., 1994). In the six sessions, a therapist worked with families and assisted them to establish a supportive family climate, recognize feelings, solve family problems, negotiate, and enjoy pleasant activities. Through a variety of exercises and roleplaying, family members were given the opportunity to work together to identify, analyze, negotiate, and solve important family problems. Table 1 summarizes the content of each session of the SNAP therapy intervention. SA who requested, or who were in need of additional treatment following completion of the six-session protocol, continued in therapy with the same clinicians. The continued treatment was based on the same principles and utilized similar techniques as those in the SNAP program. For example, when new problems arose, five procedures were followed: (a) the respective roles of the SA and the mother within the family were examined for possibly eliciting the problem; (b) the family rules maintaining the behavior problem were specified; 
Table 1

Primary Goals for Each Successful Negotiation Acting Positively (SNAP) Therapy Session

\begin{tabular}{cc}
\hline Session & Primary goals \\
\hline 1 & $\begin{array}{c}\text { Remind family of positive, mutual feelings; share compliments; establish therapist's credibility by } \\
\text { securing goals for each family member; make temporary plan for coping with suicidal feelings } \\
\text { Create family problem hierarchy; select problem of moderate intensity to practice problem- } \\
\text { solving steps } \\
\text { Analyze family obstacles (i.e., interpersonal rules, roles, and expectations regarding rules and } \\
\text { roles) that might interfere with successful problem resolution }\end{array}$ \\
3 & $\begin{array}{c}\text { Review positive coping strategies and negotiation techniques; brainstorm solutions to selected } \\
\text { moderately difficult problems } \\
\text { Brainstorm solutions for a difficult problem and evaluate solutions for coping with this problem; } \\
\text { select best solution; negotiate implementation of solution } \\
\text { Review plan for maintenance of positive family problem-solving and coping with stress; reiterate } \\
\text { family rules and roles; review successes during treatment program and address any termination } \\
\text { issues }\end{array}$ \\
\hline
\end{tabular}

(c) the contingencies encouraging the problem behavior were changed; (d) the meaning of the continued problems within the family were reviewed; and (e) new skills were taught. Therapists, SA, and mothers completed post-session evaluations of improvement, rated on scale from 1 (very much improved) to 7 (very much worse); the quality of care provided, rated on a scale from 1 (not at all caring) to 5 (very caring); and comfort in the therapy session, rated on a scale from 1 (not at all comfortable) to 5 (very comfortable), with higher scores indicating a more positive response. Overall, improvement was rated high by the therapists $(M=5.70, S D=0.59)$, the $\mathrm{SA}(M=5.88, S D=0.69)$, and the mothers $(M=5.62, S D=0.63)$. The post-session ratings of therapeutic improvement were higher over time across the six sessions of the SNAP therapy. For example, therapists' mean ratings of improvement were $M=5.4$ $(S D=0.63)$ for sessions 1 and $2, M=5.9(S D=0.70)$ for sessions 3 and 4 , and $M=6.3(S D=0.67)$ for sessions 5 and 6. Ratings for quality of care and comfort were similar. Overall, ratings of the quality and content of each session by the therapists $(M=4.4, S D=0.54)$, the $S A(M=4.3, S D=0.81)$, and the mothers $(M=4.2, S D=0.54)$ were also relatively high and rose slightly over time. Finally, comfort at the sessions was rated relatively high by the therapists $(M=4.1, S D=0.62)$, the SA $(M=4.09, S D=0.87)$, and the mothers $(M=3.93, S D=0.70)$.

\section{Assessments}

Emergency room assessments prior to ER care (Time 0). The attending child psychiatry fellow or adult psychiatry resident completed ratings on the Pierce Suicide Intent Scale (Pierce, 1977), a brief, 12-item clinical interview regarding: the circumstances surrounding the attempt (isolation, timing, precautions against discovery, seeking help, final acts, notes), medical lethality (predictable outcome and probability of death), the patient's expectations of lethality, and statements of intentions to die (lethality, premeditation, reaction to the act). Items were rated on a scale from 0 (low suicidal intent) to 2 (suicidal intent) and then summed to yield a single intent score $(\alpha=0.68)$ in the present sample. The 17-item Hamilton Depression Rating Scale for Depression (Hamilton, 1960; $\alpha=0.72$ ) was used to measure presenting levels of depression in the ER. Additional demographic information was obtained in a structured interview with SA and their mothers to supplement the clinical information and allow tracking of participants. The country of birth for each of the SA and mothers, the time lived in the United States, primary language, and daily use of Spanish and English were gathered to assess acculturation. The treating child psychiatrists were compensated with $\$ 75$ worth of educational materials per patient for completing the assessments.

Post-ER care baseline and follow-up assessments. Within a month (typically 10 days) of the ER care, a two-person team of interviewers visited the family at home and conducted the baseline (post-ER) interview. Follow-up interviews were conducted at 3 ( $n=122 ; 87 \%$ follow-up), 6 $(n=118 ; 84 \%), 12(n=130 ; 93 \%)$, and 18 months $(n=129 ; 92 \%)$ following the date of the initial suicide attempt. Interviewers were bilingual persons with a bachelor of arts degree who were typically graduate students and predominantly female (one male interviewer). The training was conducted over 2 weeks and included didactic instruction on interviewing, psychopathology, emergency protocols for coping with clinical crises, the use of computerized interviews, and a line-by-line review of the assessment instrument. Mock role-plays of the interview were conducted, and all interviewers were certified by supervisors prior to initiating interviewing. Training for the DISC (Shaffer et al., 1996) was conducted by experienced DISC trainers from Columbia University, Department of Child Psychiatry, and a separate certification process was conducted for the DISC.

Categories of symptomatology. As part of the post-ER assessment, SA and mothers were administered the DISC (Shaffer et al., 1996; Shaffer, Fisher, Lucas, Dulcan, \& Schwab-Stone, 2000), a highly structured, reliable, and extensively used diagnostic instrument assessing psychiatric symptomatology. The following major psychiatric diagnoses were assessed over the 6 months previous to the baseline interview: panic disorder, agoraphobia, generalized anxiety disorder and separation anxiety (anxiety disorders); major depressive disorder and dysthymia (depressive disorders); and conduct disorder and oppositional-defiant disorder (disruptive disorders). Diagnoses were generated using computerized scoring algorithms (cf. Piacentini \& Fisher, 1993). Two versions of the DISC were used, both corresponding to the Diagnostic and Statistical Manual of Mental Disorders (3rd ed., rev., DSM-III-R, American Psychiatric Association, 1987). Six SA and 34 mothers received the DISC-2.1 (Shaffer, Fisher, Piacentini, Schwab-Stone, \& Wicks, 1989), while the remainder of the sample was administered the DISC-2.3 (Shaffer et al., 1996). The differences between the two versions for the diagnoses used in the present study were slight and primarily involved the depressive disorders module; the wording and skip-out structure were simplified in the later version and the scoring algorithms were changed so that a 2-week duration for individual vegetative symptoms (e.g., sleep and appetite disturbances) was no longer required to make a positive diagnosis (Shaffer et al., 1996). Subsequently, the DISC-2.1 algorithms were modified to reflect these changes and achieve compatibility between the two versions.

Mothers and SA whose primary language was Spanish were interviewed using the Spanish version of the DISC 2.1 (Ribera et al., 1996). The Spanish DISC was translated from English to Spanish using a comprehensive crosscultural adaptation model that strove to identify similar phenomena to those identified by the original English version. The translation and adaptation process involved various methodological steps, including a bilingual committee, back-translation, and reliability and validity testing (Bravo, WoodburyFarina, Canino, \& Rubio-Stipec, 1993). Similar to the original DISC, the Spanish DISC possesses satisfactory reliability and validity characteristics.

Information from the DISC-C (child version) and DISC-P (parent version) was combined at the diagnostic level using an "or" rule (Piacentini, 
Cohen, \& Cohen, 1992). The versions of the DISC used in the current study have been shown to possess acceptable to excellent psychometric properties, especially when used with clinical populations (Fisher et al., 1993; Jensen et al., 1995; Schwab-Stone et al., 1993, 1996; Shaffer et al., 1996). Reliability between SA and maternal reports is generally higher for externalizing symptoms, rather than internalizing symptoms (Schwab-Stone et al., 1996). However, by utilizing the strategy of including a symptom if either the parent or youth reported the symptom, the problem of underreporting by parents was addressed (Piacentini et al., 1992).

SA self-reports. At each SNAP therapeutic session, as well as at each follow-up assessment, self-reports were gathered from the SA and their mothers reporting any new suicide attempts (self-injury with an intent to die that required medical attention) or reideation by the SA. Suicidal reideation was asked as a yes or no event of thinking seriously about killing oneself for a period of 2 weeks. The records in the ER at Columbia Presbyterian Medical Center were monitored to identify all admissions for suicide attempts among the sample; no reattempts were identified by monitoring ER logs that were not also reported by SA and their mothers. The Suicidal Ideation Scale (12 items; $\alpha=0.94$; J. M. Harkavy-Friedman, personal communication, May, 1994; Harkavy-Friedman \& Asnis, 1989), taken from the Harkavy Asnis Suicide Survey (HASS), was used to assess severity of current suicidality (Harkavy-Friedman, Asnis, \& DiFiore, 1985). The Columbia Presbyterian Medical Center was the predominant provider in the area; it is unlikely that SA received care at any other facility during the follow-up period. Current depression was measured with the total score of the Beck Depression Inventory (BDI; Beck, Ward, Mendelson, Mock, \& Erbaugh, 1961), a 21-item, reliable and valid (Beck, Steer, \& Garbin, 1988) self-report questionnaire in which the frequencies of depressive symptoms are rated on a scale from 0 to 3 and them summed to yield one score (range $=0$ [normal] to [extreme depression] $63 ; \alpha=.90$ ).

$S A$ and maternal self-reports. The Family Adaptability and Cohesion Evaluation Scale (FACES III; Olson, Portner, \& Lavee, 1985), a 20-item scale with acceptable reliability and validity, was completed by both the SA and their mothers (Olson, 1986; Rodick, Henggeler, \& Hanson, 1986). Two primary dimensions are scored on a 1 (almost never) to 5 (almost always) scale: (2) perceived adaptability (i.e., a family's ability to change its power structure, role relationships, and rules in response to situational and developmental stress); and (b) perceived cohesion (i.e., a family's emotional attachment). Higher scores on both dimensions are thought to reflect more adaptive functioning (Henggeler et al., 1993). The FACES III exhibited good internal reliability in the present sample ( $\alpha \geq 0.82$ for both the adaptability and cohesion subscales for SA and mothers).

Maternal self-reports. Maternal symptoms were assessed with two scales: (a) the total score on the BDI ( $\alpha=.88$; Beck et al., 1961), and (b) the mean score of a shortened version of the Symptom Check List (SCL90; Derogatis, 1974), the Brief Symptom Inventory (BSI; $\alpha=0.96$ ). The BSI measures nine dimensions of distress: somatization, obsessivecompulsiveness, interpersonal sensitivity, depression, anxiety, hostility, phobic anxiety, paranoid ideation, and psychoticism. Mothers also completed the FACES III as described previously ( $\alpha>0.82$ for subscales of perceived family adaptability and cohesion scales).

Treatment attendance was defined as the number of sessions attended by each family member and was systematically collected from clinicians and monitored by a computerized tracking program. This tracking continued throughout the duration of the 18-month follow-up period. Therapists followed standardized procedures for scheduling appointments, reminding clients of appointments, and closing cases.

\section{Statistical Analysis}

Longitudinal analyses were based on a multivariate extension of the linear mixed model described by Laird and Ware (1982), using software developed by Schafer (1998) to accommodate multiple longitudinal outcomes. This method accommodates missing outcomes at specific time points and incorporates observed outcomes at the same time point to produce multiple imputations (Rubin, 1987). This approach is apt to have advantages over treating each incomplete variable separately in univariate linear mixed models, even though separate univariate mixed models were eventually applied to the multiply-imputed data sets, since associations observed in the multivariate data set were used to impute for missing values. The potential for this strategy to improve the precision of estimation is discussed further in Belin, Piacentini, Rotheram-Borus, and Song (1997), and in Liu, Taylor, and Belin (1995).

Once the data had been completed through multiple imputation, models were fit to assess the effects of intervention condition (specialized vs. standard ER care condition), number of outpatient SNAP therapy sessions attended by the SA, and number of outpatient sessions attended by the mothers. In each of these models, additional covariates included indicators for baseline symptomatology, single-parent household, whether the mother had more than 12 years of education, and ordinal measures of both the SA's and their mothers' levels of acculturation (which were treated as continuous covariates). The first model also included interaction effects between symptomatology and intervention, the second model included interaction effects between symptomatology and the number of SNAP sessions attended by the $\mathrm{SA}$, and the third model included interaction effects between symptomatology and the number of outpatient SNAP sessions attended by the mother. With a sample size of 140 participants and 11 variables in the model, there did not appear to be problems in fitting the models to the data.

Prior to fitting these models, symptomatology status was missing for 3 cases, the indicator for mother's education was missing for 19 cases, and acculturation measures were missing for one SA and 16 parents prior to fitting these models. These missing baseline covariates were multiply-imputed using a multivariate normal model (Schafer, 1997) that included average values of the longitudinal outcome measures and all covariates. For binary variables, the imputed values from the multivariate normal model were treated as probabilities of a 1 versus a 0 , and these values were used to impute zeros and ones for missing binary characteristics. After producing three imputations under this model, the longitudinal model was fit to each imputed data set and results were combined according to the framework for multiple imputation inference ( $\mathrm{Ru}$ bin, 1987). When the degrees of freedom for the approximate $t$ reference distribution for multiple imputation inference exceeded 100, we used $d f=100$ for our calculations. Because patterns over time were generally similar across imputations, our figures present results from a single imputed data set for ease of interpretation.

A final set of analyses considered time until first sign of suicidal reideation and time until first sign of suicide reattempt. Because measurements were only taken at discrete time points $(3,6,12$, and 18 months post-baseline), we used the method of Prentice and Gloeckler (1978) for grouped survival data in these analyses, which provides a discrete analog to the continuous proportional hazards model. The same covariates were used in these analyses as in the longitudinal analyses of continuously scaled outcomes. The follow-up rates across time were high (range $=$ $84 \%-93 \%$ ), yet we used analytic strategies to adjust for missing data. Data on suicidal reideation were missing for $18,21,10$, and 11 cases at $3,6,12$, and 18 months, respectively, and data on suicide reattempt were missing for $35,22,10$, and 11 cases at $3,6,12$, and 18 months, respectively. Missing items for these analyses were multiply-imputed using log-linear models for incomplete categorical data (Schafer, 1997), with a model selection procedure that allowed significant interaction terms to enter the models. Reported results were again based on multiple imputation inferences.

We adapted the framework from Murray (1998) for detecting power in a repeated-measures context to accommodate missing data by incorporating a term for missing information in the formula for detectable differences (Murray, 1998, p. 364). If there was no missing information, the sample size for comparing intervention arms was sufficient to detect an effect size of $0.3 S D$ or more at $\alpha=0.05$, with at least $80 \%$ power so long as the within-subject intracluster correlation (ICC) was less than 0.24 , which is higher than was seen for most of the outcomes we considered. For comparisons between impairment groups, the detectable differences at $80 \%$ power were $0.37 S D$ if the ICC $<0.24$, assuming no adjustment for 
Table 2

Demographic Status of Adolescent Suicide Attempters (SA) and Their Mothers in the Standard Emergency Room (ER) Care and in the Specialized ER Care Conditions (Rotheram-Borus, Piacentini, Van Rossem, et al., 1996)

\begin{tabular}{|c|c|c|c|}
\hline Demographic & $\begin{array}{l}\text { Standard care } \\
\quad(n=75)\end{array}$ & $\begin{array}{l}\text { Specialized care } \\
\quad(n=65)\end{array}$ & $\begin{array}{c}\text { Total } \\
(n=140)\end{array}$ \\
\hline \multicolumn{4}{|l|}{ SA characteristics } \\
\hline \multicolumn{4}{|l|}{ Age } \\
\hline$M$ & 14.9 & 14.9 & 14.9 \\
\hline$S D$ & 1.5 & 1.4 & 1.4 \\
\hline Latino $(\%)$ & 85.3 & 89.2 & 87.1 \\
\hline Held back in school $(\%)$ & 30.3 & 41.5 & 35.7 \\
\hline Ever attended remedial classes (\%) & 10.0 & 9.3 & 9.6 \\
\hline Suicidal intent (Pierce, 1977) (n) & 65 & 54 & 119 \\
\hline$M$ & 5.0 & 4.8 & 4.9 \\
\hline$S D$ & 3.54 & 3.30 & 3.42 \\
\hline Depression (HAMD) $(n)$ & 60 & 59 & 119 \\
\hline$M$ & 5.5 & 5.9 & 5.7 \\
\hline$S D$ & 4.8 & 4.5 & 4.6 \\
\hline Method (\% ingestion) & 86.6 & 94.3 & 90.0 \\
\hline Previous attempt $(\%)$ & 29.7 & 31.8 & 30.7 \\
\hline \multicolumn{4}{|l|}{ Maternal characteristics } \\
\hline Age at adolescent's birth $(n)$ & 57 & 52 & 109 \\
\hline$M$ & 24.12 & 25.00 & 24.54 \\
\hline$S D$ & 6.06 & 4.89 & 5.53 \\
\hline Level of education $(n)$ & 61 & 60 & 121 \\
\hline$M$ (year) & 9.43 & 9.82 & 9.62 \\
\hline$S D$ & 3.80 & 3.85 & 3.81 \\
\hline \multicolumn{4}{|l|}{ Marital status (\%) } \\
\hline Married to child's father & 20.0 & 30.0 & 24.6 \\
\hline Married to other & 24.3 & 21.7 & 23.1 \\
\hline Never married & 18.6 & 8.3 & 13.8 \\
\hline Separated, divorced, widowed & 37.1 & 40.0 & 38.5 \\
\hline Other & 0.0 & 0.0 & 0.0 \\
\hline \multicolumn{4}{|l|}{ Language (\%) } \\
\hline English only & 13.3 & 7.7 & 10.7 \\
\hline Spanish only & 62.7 & 63.1 & 62.9 \\
\hline Spanish and English & 24.0 & 27.7 & 25.7 \\
\hline English and other & 0.0 & 1.5 & 0.7 \\
\hline \multicolumn{4}{|l|}{ Employment status (\%) } \\
\hline Full-time work & 33.8 & 31.1 & 32.6 \\
\hline Part-time work & 4.4 & 9.8 & 7.0 \\
\hline Homemaker & 45.6 & 52.5 & 48.8 \\
\hline
\end{tabular}

Note. $\mathrm{HAMD}=$ Hamilton Depression Inventory.

multiple comparisons, rising to $0.43 S D$ if a Bonferroni correction was incorporated. With $20 \%$ missing information, which was higher than was seen for most of the outcomes we considered, the detectable difference at $80 \%$ power became $0.40 S D$, ignoring multiple comparisons, or $0.47 S D$ including a Bonferroni correction.

\section{Results}

\section{Description of the Sample and the Suicide Attempts}

Comparisons of the SA and their mothers in the specialized ER care and the standard ER care conditions prior to receipt of any ER intervention (Time 0) are presented in Table 2. Overall, the mean age of the $S A$ was 15 years ( $S D=2$ years, range $=12-18$ years), and $87.1 \%$ were Dominican or Puerto Rican. On average, SA were in ninth grade; $35.7 \%$ had been held back at least one grade, and $9.6 \%$ had attended remedial classes. The most common method of suicide attempt was ingestion $(90 \%)$, and for $31 \%$, this was a second suicide attempt. Mothers had generally received a ninth-grade education and were of lower socioeconomic status.
Most mothers were in their mid-20s when their children were born. Currently, 25\% were married to their child's father, $23 \%$ were remarried to another person, $13.8 \%$ had never been married, and $38.5 \%$ were separated, divorced, widowed, or had another type of marital status. Most mothers spoke only Spanish $(62.9 \%)$ or were bilingual $(25.7 \%)$. About one third of the mothers worked full time. A fuller description of the sample is available (Rotheram-Borus, Piacentini, Van Rossem, et al., 1996). When rated in the ER, the overall suicidal intent was $4.9(S D=3.4)$ and the depression score on the Hamilton Depression Inventory (Hamilton, 1960) was $5.7(S D=4.5)$. A series of $t$ tests were used to compare the two intervention conditions on background characteristics and measures collected in the ER prior to the delivery of the care. There were no significant differences on ER assessments between those receiving specialized $E R$ care and those receiving standard ER care on any sociodemographic characteristic, initial levels of depression, suicide intent, mental health status, or substance abuse. Please note that the longer baseline interview was 
Table 3

Results of Linear Mixed Model Regression for Outcomes of Adolescent Suicide Attempters (SA) Based on Intervention Condition (Specialized or Standard Care) Indicating Betas and the Level of Significance

\begin{tabular}{lcccc}
\hline \multicolumn{1}{c}{ Category } & Depression & $\begin{array}{c}\text { Suicide Ideation } \\
\text { (HASS) }\end{array}$ & $\begin{array}{c}\text { Adaptability } \\
\text { (FACES III) }\end{array}$ & $\begin{array}{c}\text { Cohesion } \\
\text { (FACES III) }\end{array}$ \\
\hline Intercept & $5.901^{* *}$ & $1.989^{*}$ & $25.981^{* *}$ & $35.502^{* *}$ \\
Time & $-0.043^{* *}$ & $-0.056^{* *}$ & $-0.080^{*}$ & -0.026 \\
Symptomatology & & & & \\
$\quad$ (M vs. L) & 0.501 & 0.369 & -1.938 & -1.306 \\
$\quad$ (H vs. L) & $1.520^{* *}$ & $1.440^{* *}$ & -1.039 & -2.981 \\
Intervention & $-0.546^{* *}$ & -0.316 & 0.413 & -1.752 \\
Mother's education & -0.139 & -0.168 & 0.546 & -1.486 \\
Family type & -0.065 & 0.083 & -1.092 & -1.065 \\
Acculturation SA & 0.007 & 0.005 & -0.127 & 0.043 \\
Acculturation mother & -0.004 & 0.004 & 0.067 & -0.112 \\
Symptomatology $\times$ Intervention & & & & \\
$\quad$ (M vs. L) & $0.941 \dagger$ & 0.478 & 0.819 & -2.225 \\
(H vs. L) & 0.170 & 0.159 & -0.306 & 1.263 \\
\hline
\end{tabular}

Note. $\quad$ HASS = Harkavy Asnis Suicide Survey; FACES III = Family Adaptability and Cohesion Evaluation scales; $\mathbf{M}=$ moderate; $\mathbf{L}=$ low; $\mathrm{H}=$ high.

$\dagger p<.10 .{ }^{*} p<.05 . \quad{ }^{* *} p<.01$.

administered after the delivery of the ER intervention (post-ER assessment); at that point, there were observed differences in depression that reflect exposure to the ER condition.

\section{Classification of the SA Based on Initial Symptomatology}

Overall, $38 \%$ of the SA met criteria for a current anxiety disorder, $44 \%$ for an affective disorder, and $24 \%$ for a disruptive behavior disorder. Overall, $43 \%$ of the SA reported no diagnosis, $21 \%$ had one diagnosis, and $36 \%$ had more than one diagnosis. Among those with a diagnosis, $44 \%$ of SA met criteria for a depressive disorder (major depressive episode $=39 \%$; dysthymia $=39 \%$ ), $38 \%$ for an anxiety disorder (generalized anxiety disorder $=22 \%$; separation anxiety $=17 \%$; agoraphobia $=15 \%$; panic disorder $=4 \%$ ), and $24 \%$ for a disruptive behavior disorder (oppositional defiant disorder $=17 \%$; conduct disorder $=17 \%$ ). The SA were classified into subgroups of relatively equal size based on the number of symptoms reported by themselves or their mothers. Given the sample size, it was not possible to examine outcomes within multiple diagnostic subclassifications of the SA. Previous research (Rubio-Stipec, Shrout, Canino, et al., 1996) has demonstrated the reliability and validity of continuous scale scores generated with the DISC 2.1 symptom counts; therefore, we used the level of SA's symptomatology to classify the SA as: (a) low symptomatology with $0 \%-14 \%$ of symptoms positive (impairment $M=0.07, S D=0.04$, range $=0.00-0.14$ ); (b) moderate symptomatology with $15 \%-54 \%$ of symptoms positive (impairment $M=0.31, S D=0.12$, range $=0.16-0.54$ ); and (c) high symptomatology with $>55 \%$ symptoms positive (impairment $M=0.95, S D=0.33$, range $=0.55-1.92$ ). The number of symptoms was selected to generate subgroups of about equal sizes.

\section{Impact of the ER Intervention Over Time on the SA and Their Mothers}

A complete description of treatment attitudes among the SA and their mothers is provided in Rotheram-Borus, Piacentini, Van Ros- sem, et al. (1996). The baseline (post-ER) assessment in this report followed the delivery of the ER condition by a few days to a maximum of 1 month, a time period that was similar across conditions.

Suicidal behavior. The base rate on suicide reattempts was very low throughout the 18-month follow-up period: 3 months- $-6.0 \% ; 6$ months $-9.8 \%$; 12 months $-12.4 \%$; and 18 months $-12.4 \%$. Eleven $\mathrm{SA}$ in the standard care condition and six SA in the specialized care condition re-attempted suicide over 18 months. Reattempts were similar across condition, however, the base rate was so low as to not allow meaningful comparisons across conditions. The cumulative rate of first reemergence of suicidal ideation rate was: 3 months$14.5 \%$; 6 months $-23.1 \% ; 12$ months $-27.9 \%$; 18 months $-29.8 \%$. There were no differences in reideation based on the ER care condition. Time to suicidal reideation varied based on the number of sessions attended by the SA. The analysis suggests that participation in seven or more sessions is protective for youth with low or moderate symptomatology, $t(24)=1.82, p<.081$; however, a significant interaction effect indicated elevated rates of reideation among highly symptomatic youth who attended seven or more sessions, $t(100)=2.45, p<.015$. These data were consistent with our initial hypothesis regarding the level of symptomatology limiting our impact to reduce risk for suicide reattempt. While suicidal reideation increases cumulatively over time, the increments in additional reideation decrease over time. This pattern suggests that a vulnerable period for reattempts is likely to occur closer in proximity to a previous attempt.

Adolescent outcomes. Table 3 summarizes the results of the linear mixed model for the SA and Table 4 summarizes the maternal outcome measures, examining variations associated with time, initial level of symptomatology, intervention condition, and intervention by symptomatology interactions, controlling for mother's education level, family status, and acculturation of mother and SA. The SA's depression varied significantly by time, $t(100)=9.26, p<.001$, symptomatology level, $t(100)=3.52$, $p<.001$, and intervention condition, $t(100)=2.82, p<.005$, and the symptomatology by intervention interaction tended to be sig- 


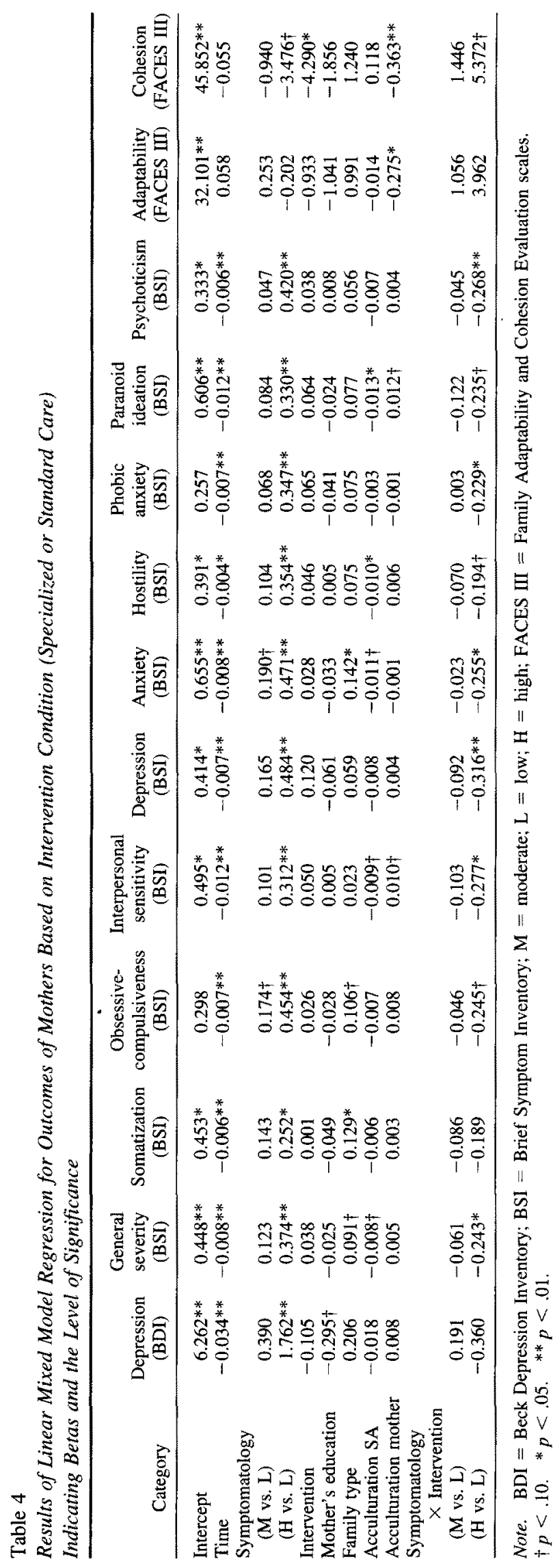

nificant, $t(100)=1.71, p<.088$. Figure $2 \mathrm{~A}$ illustrates the differences in depression at each follow-up assessment over 18 months based on intervention condition; please note that the baseline differences in the level of depression were not evident in the ER, prior to the delivery of the differential ER care. The behaviors observed on the post-ER interview reflect differences associated with the delivery of the specialized ER care and the standard ER care. The clinical significance of these differences is demonstrated when examining the percentage of SA in each intervention condition whose scores on the BDI were in the clinical range. At Time 1, following the delivery of the ER intervention, $30 \%$ of the SA in the standard ER care and $22 \%$ in the specialized ER care reported BDI scores in the clinical range. This difference remained over 18 months, as shown in Table 5. Figure 2B demonstrates the differences in depression over time between SA with low and high symptomatology. Reports of depression from the SA with low symptomatology, $t(100)=2.82, p<.005$, were also significantly lower in the specialized ER care condition; there was some indi-

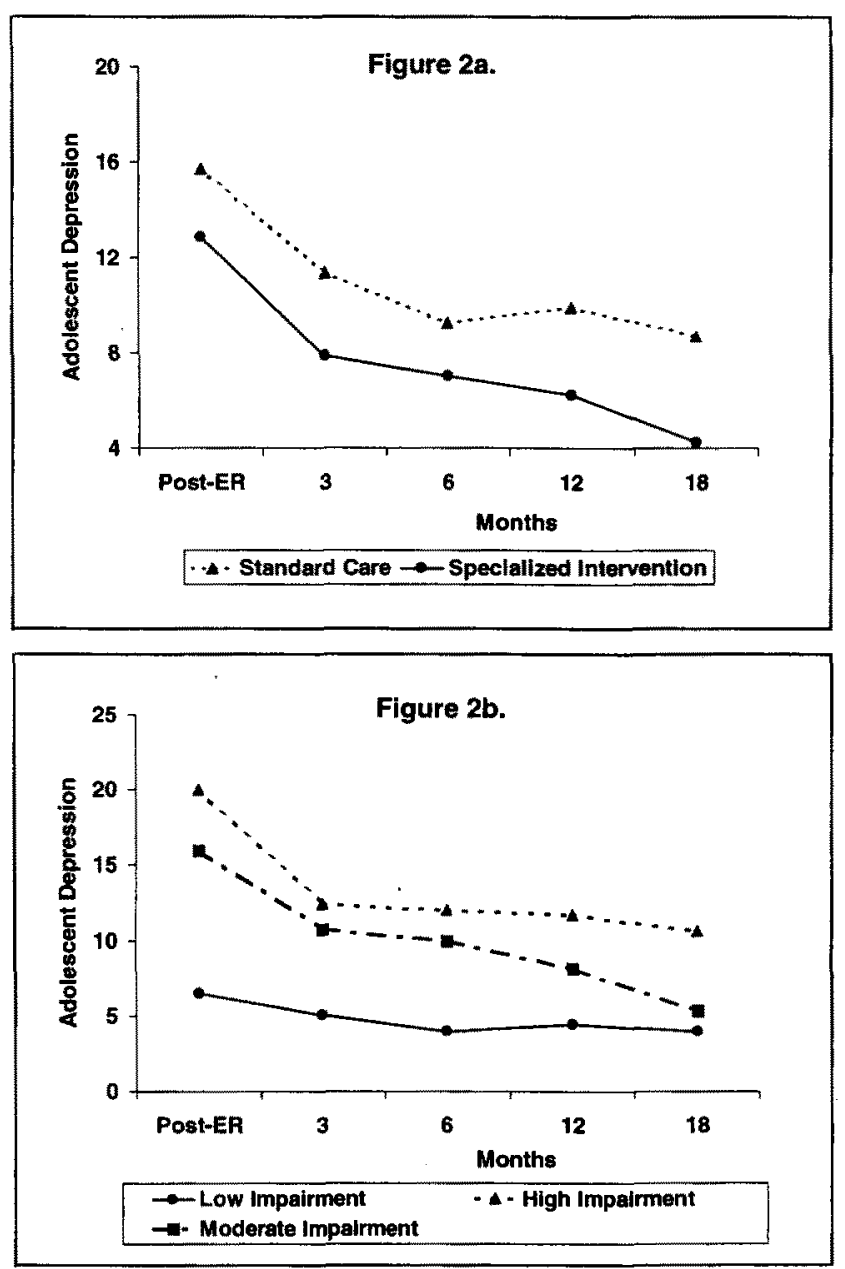

Figure 2. (A) Plot of the mean scores on the Beck Depression Inventory of suicide attempters at baseline and 3, 6, 12, and 18 months for adolescents in the Specialized and the standard emergency room care conditions. (B) Plot of the mean scores on the Beck Depression Inventory of suicide attempters at baseline and 3,6,12, and 18 months for adolescents of low, moderate, and high symptomatology. 
Table 5

Percentages of Suicide Attempters and Their Mothers Whose Scores on The Beck Depression Inventory Were Above the Clinical Cutoff Point at Each Follow-Up Period

\begin{tabular}{lccccc}
\hline \multicolumn{1}{c}{ Group } & Post-ER & Month 3 & Month 6 & Month 12 & Month 18 \\
\hline Suicide attempters & & & & & \\
Standard ER care & 29.7 & 16.4 & 9.7 & 17.9 & 10.1 \\
Specialized ER care & 21.9 & 10.0 & 8.3 & 9.7 & 4.9 \\
Overall & 26.1 & 13.2 & 9.0 & 14.0 & 7.7 \\
Mothers & & & & & \\
Standard ER care & 26.2 & 11.9 & 16.7 & 10.0 & 18.3 \\
Specialized ER care & 12.1 & 8.6 & 5.0 & 3.4 & 1.8 \\
Overall & 19.5 & 10.3 & 10.8 & 6.8 & 10.3 \\
\hline
\end{tabular}

Note. $\mathrm{ER}=$ Emergency room.

cation of a treatment by symptomatology interaction effect suggesting elevated depression levels in the moderate symptomatology group in the specialized ER care condition, $t(100)=1.71, p<$ .088. There were no significant differences on HASS suicidal ideation scores in family cohesion or adaptability based on SA's reports.

Maternal outcomes. Maternal reports of depression on the BDI were not in the clinical range $(M=11.5, S D=9.4)$, and mothers' scores on the BSI were in the mildly clinical range $(M=0.63, S D=0.6)$. There was an intervention by symptomatology interaction on the BSI General Severity Index, $t(100)$ $=2.39, p<.018$, where mothers of highly symptomatic SA in the standard ER care condition had elevated levels of emotional distress, but mothers of highly symptomatic SA in the specialized ER care condition had levels of distress similar to those in mothers of moderate- and low-symptomatology SA. The pattern of emotional distress reported by mothers in each intervention condition of SA with varying levels of symptomatology is shown in Figure 3. Similar findings were reported on the remaining BSI subscales. For example, lower levels of depression were reported by mothers with highly symptomatic daughters in the specialized ER care condition compared with those in the standard ER care condition. Although mothers with highly symptomatic daughters in the standard ER care condition were significantly more anxious than those with daughters with low symptomatology, $t(100)=4.00, p<$ .001 ), the elevation of anxiety was significantly lower for mothers of highly symptomatic children in the specialized ER care condition, $t(100)=2.02, p<.04$. To examine the clinical significance of these findings, the percentage of mothers reporting scores on the BDI in the clinical range are shown on Table 5. At the post-ER assessment, $12.1 \%$ of mothers in the specialized ER care condition reported scores on the BDI in the clinical range, versus $26.2 \%$ of mothers receiving standard ER care, a $14 \%$ difference. This difference persisted over 18 months.

Mothers tended to rate their family relationships as being significantly more cohesive $(M=63.7, S D=12.5)$ than did their daughters $(M=54.2, S D=12.4)$. There was a significant difference in maternal ratings of cohesion based on intervention condition, $t(100)=2.04, p<.04$, as shown in Figure 4. Ratings of family cohesion tended to be significantly different among mothers of adolescents based on an intervention condition-bysymptomatology interaction, $t(100)=1.77, p<.08$. Mothers of SA who were low or moderately symptomatic in the specialized ER care condition tended to report that their families were less cohesive, $t(100)=1.82, p<.069$. The extent of the difference between intervention groups was not as great among mothers of highly symptomatic SA.

We also examined whether the outcomes varied as a function of the number of sessions attended as a predictor (rather than intervention condition). The number of sessions was unrelated to the outcome variables, controlling for other covariates.

\section{Variations in Outcomes Associated With Treatment Attendance}

We hypothesized that attendance in the SNAP therapy program also would be associated with differences in outcomes for the SA and mothers in the specialized ER care condition. As previously reported (Rotheram-Borus, Piacentini, Van Rossem, et al., 1996, 1999), the specialized ER condition increased attendance at subsequent outpatient treatment for the SA, but not for the mother. SA in the specialized ER care condition attended 3.8 more therapy sessions on average than those in the standard ER care condition. The number of sessions attended was not normally distributed; in

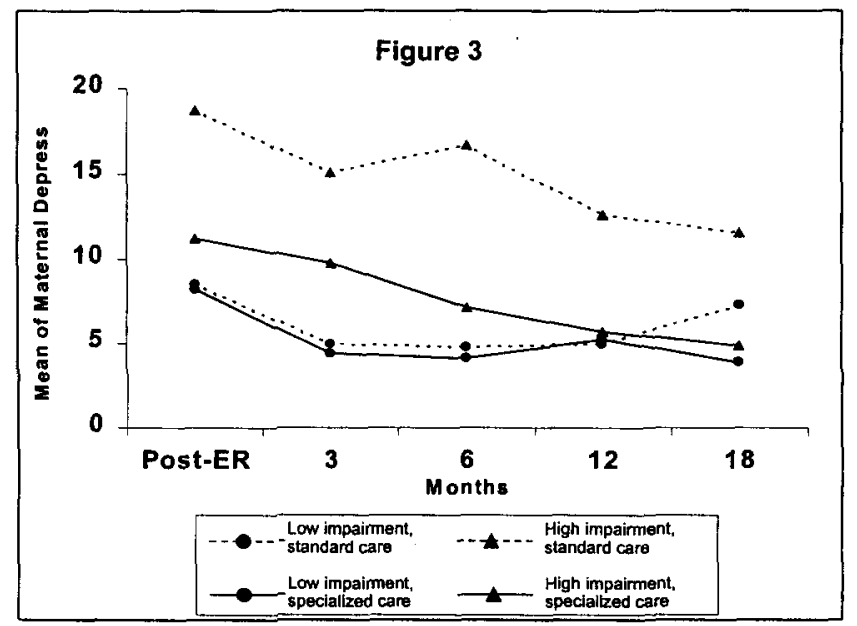

Figure 3. Plot of maternal depression on the Brief Symptom Inventory at baseline and 3, 6, 12, and 18 months for four groups: low symptomatology, standard emergency room (ER) care; high symptomatology, standard ER care; low symptomatology, specialized ER care; and high symptomatology, specialized ER care. 


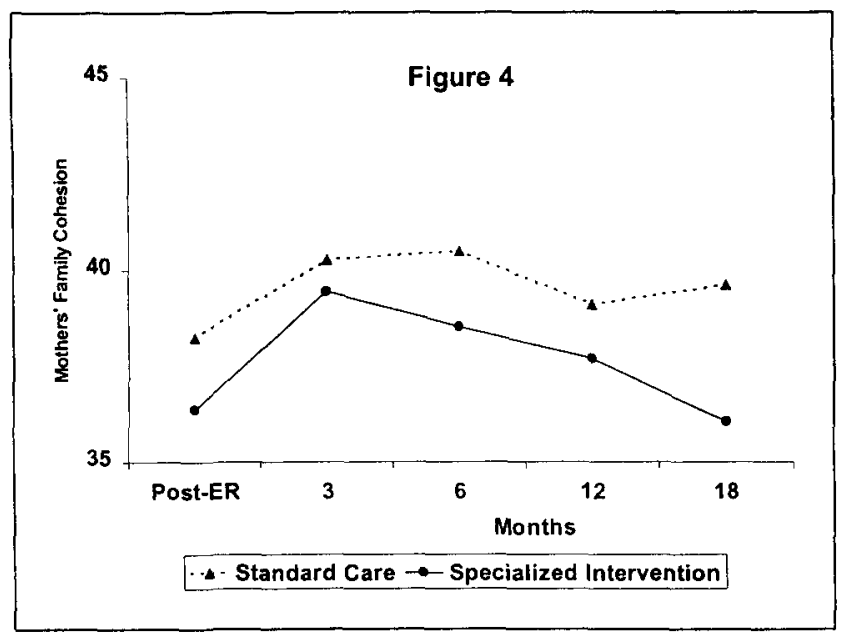

Figure 4. Plot of ratings of family cohesion at baseline and 3, 6, 12, and 18 months for mothers in the specialized and the Standard emergency room care conditions.

particular, the range on the number of sessions was large, with a few SA who continued in therapy for about 1 year. Because the initial goal was to complete the SNAP 6-session treatment, we divided the sample into three subgroups: (a) those who did not adhere to treatment (i.e., those who received 0-2 sessions), (b) those who basically adhered to the SNAP treatment and attended 3-6 sessions, and (c) those who required more intervention than initially designed in the SNAP treatment (i.e., those attending 7 or more sessions). Figures $5 \mathrm{~A}$ and $5 \mathrm{~B}$ show the percentage of mothers and SA across conditions attending $0-2$ sessions (nonadherent), 3-6 sessions (there were 6 sessions in SNAP), or more than the complete dose ( $\geq 7$ sessions of outpatient treatment).

There was a significant relationship between intervention condition and adherence among SA, $\chi^{2}(2, N=140)=6.9, p<.03$, but not among their mothers, $\chi^{2}(2, N=140)=4.1, p<.128$. Given these data, a linear mixed model regression analysis examined the relationship between attendance and indices of adjustment. While there were significant variations in the number of sessions attended for the SA, attendance was not typically related to SA's outcomes over time. Only one significant finding emerged, namely that SA who attended 3-6 sessions versus those who attended $0-2$ sessions had significantly higher levels of family adaptability, $t(100)=2.03, p<.04$, among SA with moderate symptomatology, in contrast to SA with low levels of symptomatology. Attendance of mothers at sessions was not consistently associated with outcomes for either the SA or the mothers over time.

\section{Discussion}

This study examined the impact over time of an ER intervention among adolescent female SA who presented different levels of psychiatric symptomatology at first visit. The strengths of the methodology were that a consecutive cohort was recruited, assessments were completed prospectively and were relatively comprehensive in scope, systematic monitoring of both adolescent and maternal treatment attendance to a standardized treatment (SNAP) was conducted, and the quality of the delivery of each component was monitored. While the number of missed follow-up assessments at each specific time was low (range $=7 \%-16 \%$ ), we were able to impute missing values at these time points with sophisticated analytic procedures, and to conduct analyses to examine the effects of both the specialized ER care program and the SNAP therapy intervention. An important aspect of the study was that the SA and mothers in the different ER care conditions were very similar in background factors, characteristics of their attempts, and psychiatric symptomatology when they were initially presented in the ER. Unfortunately, the sample was limited to female SA who were primarily Hispanic and from only one hospital in New York City.

In this hospital, a specialized ER care intervention allowed us to examine the impact of brief structural interventions on adolescent and parent outcomes. Random assignment was not possible because the intervention addressed multiple aspects of the ER experience, creating a new routine for managing suicide attempters among many different types of staff (receptionists, guards, pediatricians, therapists, psychiatrists). Contamination would have destroyed any possible randomized design.

The rate of suicide reattempts was lower in this study than previously reported in the literature (see Shaffer \& Piacentini,
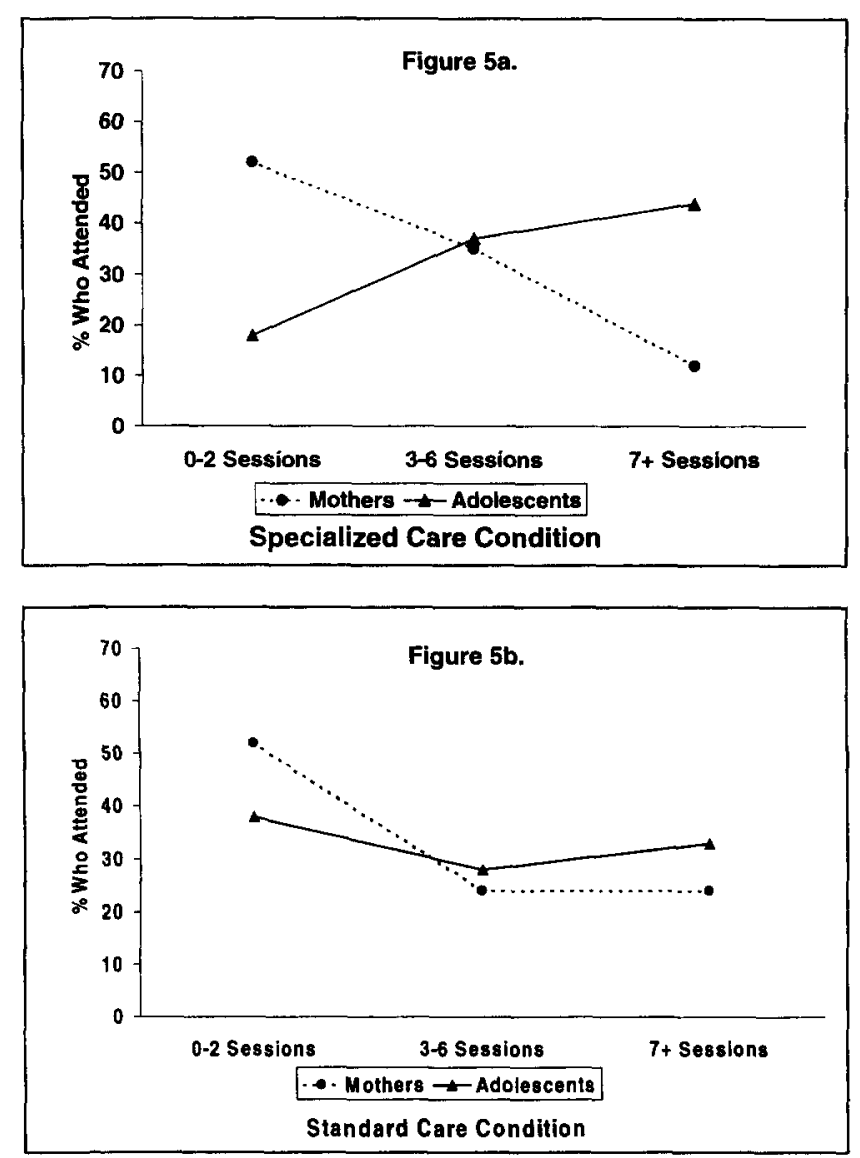

Figure 5. (A) Plot of the percentage of mothers and adolescents who attended varying numbers of therapeutic sessions $(0-2 ; 3-6 ; \geq 7$ sessions $)$ in the specialized emergency room Care condition $(n=65)$. (B) Plot of the percentage of mothers and adolescents who attended varying numbers of therapeutic sessions $(0-2 ; 3-6 ; \geq 7$ sessions $)$ in the standard emergency room care condition $(n=75)$. 
1994, for a review). Prior to the initiation of this study, we had anticipated a suicide reattempt rate of about $45 \%$; yet the cumulative rate of rẹattempts over 18 months was only $12.4 \%$. While there were more attempts in the standard ER care condition (11 vs. 6), with such a low base rate and small sample size, we lacked the power to detect differences in suicide reattempts based on ER care condition. This low base rate may reflect the efficacy of the SNAP treatment, but this study was not designed to evaluate this question. A future study must examine if the SNAP treatment is associated with a lower base rate of suicide reattempts. The rates of suicidal reideation were $14.5 \%$ at 3 months and $29.8 \%$ at 18 months. Therefore, the period immediately following the suicide attempt was the time of highest risk for another suicide attempt, as shown in the survival analysis. The rate of suicidal reideation was similar across ER intervention conditions, which was expected. Both the specialized ER care condition and the SNAP therapy emphasized that feeling suicidal was normative and a signal for taking behavioral actions to stop progression to suicidal acts. Feelings and ideation were distinguished from suicide attempts, as attempts are physically dangerous and anxiety-producing for the SA, families, and therapists. Therefore, we did not anticipate differences in suicidal ideation as a function of the intervention.

Consistent with the data previously reported (Rotheram-Borus, Piacentini, Van Rossem, et al., 1996), over 18 months, the brief structural intervention in the specialized ER care condition was associated with greater attendance ( 3.8 sessions) and completion of the SNAP therapy ( $81 \%$ vs. $61 \%$ ) compared with the standard ER care condition. As previously reported, parents in the specialized ER care condition also reported more positive attitudes toward treatment and described their "ideal" family to be more adaptive and cohesive than did parents in the standard ER care condition (Rotheram-Borus, Piacentini, Van Rossem, et al., 1996). Therapists often assume that youth benefit from attending therapy. However, when the impact of both the ER intervention condition and participation in the SNAP treatment were simultaneously evaluated, the specialized ER care condition was associated with greater benefits.

The specialized ER care intervention was associated with lower levels of depression for both the SA and their mothers immediately following the ER encounter (Rotheram-Borus, Piacentini, Van Rossem, et al., 1996). These differences persisted over the next 18 months, although they were greater among mothers than the SA. The mothers in the specialized ER care condition consistently reported less depression and fewer mental health symptoms over 18 months than mothers whose daughters received standard ER care. About $14 \%$ fewer mothers and 5\% fewer SA reported BDI scores in the clinical range over the 18 month follow-up period. Conversely, mothers of highly symptomatic daughters who received the standard ER care condition reported greater depression, more mental health symptoms, and less positive perceptions of their family over the next 18 months. These results are impressive given the relatively low cost of delivering the specialized ER care condition. In contrast, greater attendance and adherence to the intervention were associated with only one significant difference: SA's ratings of family adaptability.

Although few studies have examined the efficacy of treatments for adolescent suicidality, a handful of recent reports have demonstrated the benefit of structured psychotherapeutic interventions for adolescent depression (Brent et al., 1997; Harrington, Whittaker, \& Shoebridge, 1998). The findings from the present study are similar to those of Renaud et al. (1998), who found only one positive result in response to a family-focused cognitivebehavioral therapy for depression (an intervention very similar to the treatment used in this study): symptoms of depression remitted more quickly for youth in the intervention condition compared with those in the control condition.

Unfortunately, the design of the present study does not allow for a clear understanding of the mechanism of change. It is possible that these findings result from parents shifting their perceptions of the cause, meaning, and consequences of suicide attempts, similar to the way shifts in perceptions have been associated with positive outcomes for other diseases (Taylor, Wayment, \& Collins, 1993). While we assessed attitudes toward treatment, we did not examine perceptions of suicidality and the meaning of the SA's suicide attempt among family members. It may be that the high emotion and crisis atmosphere generated by an ER visit present a window of opportunity for altering preexisting expectations of SA and their mothers. The anger and blaming that typify ER encounters for suicidal youth and their parents (Miller, Rotheram-Borus, Piacentini, Graae, et al., 1992) are reduced. Rather than having the ER encounter exacerbate and solidify negative interaction patterns, families in the specialized ER care condition were provided with an alternative style of understanding the suicide event. The therapists focused on eliciting expressions of caring between SA and their mothers, identifying their personal strengths, and planning strategies for processing future suicidal feelings by the SA. In combination with increasing staff training and skills to cope with suicidal youth, the ER experience assisted in setting accurate, positive expectations for the family's outpatient therapeutic experience. Surprisingly, these procedures positively influenced outcomes over the next 18 months. Future research must examine SA's and their mothers' conceptualization of the suicide attempt prior to and following structural interventions, such as the specialized ER care condition, and examine if shifts in perceptions are responsible for the ongoing benefits of the intervention. These findings also suggest that parents are important targets of interventions for female adolescents demonstrating suicidal and depressed behaviors.

SA with low levels of mental health symptoms, when presented at the ER, reported lower levels of depression over 18 months, independent of the SNAP treatment attended or the type of ER care provided. This finding was consistent with our a prior hypotheses. However, we hypothesized that the specialized ER care would also have the greatest effect among those SA with moderate symptomatology. This did not occur. The parents of SA who were highly symptomatic demonstrated the greatest reductions in emotional distress over time. While we focused on the results for global distress, depression, and anxiety, there were also significant reductions in a number of other subscales of the BSI: somatization, obsessive-compulsive behavior, interpersonal sensitivity, hostility, phobic anxiety, paranoid ideation, and psychoticism.

The mothers in the specialized ER care condition also reported that their families were less cohesive over time. It is possible that mothers perceived themselves as less involved in their children's adjustment and, therefore, the mothers' emotional distress decreased. The present sample consisted primarily of first-generation Puerto Rican and Dominican families in which the suicide attempts were often precipitated by a family fight regarding restricted independence for the adolescent (Miller, Rotheram-Borus, Piacentini, Graae, et al., 1992). Yet, based on the FACES data, 
only $3.5 \%$ of the SA and $12.5 \%$ of mothers indicated that the families were over-enmeshed at the baseline assessment; most families were disengaged or separated.

The rates of therapeutic adherence were significantly higher among participants in both the standard and specialized ER care conditions than have been previously reported in the literature (Trautman, Stewart, \& Morishima, 1993; Spirito et al., 1989). In the same hospital, Piacentini et al. (1995) reported a treatment adherence rate of about $25 \%$. To implement the study, the routine ER care was standardized and procedures routinized to process all suicidal youth. Standardizing procedures may enhance therapeutic adherence (Piacentini et al., 1995), and the improvements may be even greater when the specialized ER care procedures are implemented. In addition, the process of repeated assessments may provide benefits to families and should also be systematically examined in future research.

It is possible that some effects were not found to be significant because the sample size was 140 participants. Given the power analysis described in the Statistical Analysis section, it is not surprising that some intervention and impairment effects were detectable since the study had adequate power to detect moderate effect sizes. However, there may be some real differences between the outcomes for the specialized and the standard ER care that the study did not detect. Furthermore, since interaction effects are apt to be smaller in magnitude than main effects, nonsignificant findings for certain interaction effects may be due to lower power (Aiken \& West, 1991).

Given the increasing move toward managed care, the costeffectiveness of this intervention and other structural interventions in care settings needs to be examined. The primary cost for the ER intervention is the presence of the bilingual crisis therapist to conduct the family session. Triage of suicidal youth in the ER typically requires an evaluation of the youth and the youth's family; expanding this evaluation to a semistructured clinical therapeutic session entails a relatively modest cost. The videotape and staff training manuals are available at relatively low cost $(\$ 20)$ in English and Spanish. We have evidence that there are modest benefits to the parents and the youth from this type of structural change. To identify whether these benefits also accrue to the providers of care, it is crucial to assess, over time, the other health care services utilized by suicidal youth.

\section{References}

Aiken, L. S., \& West, S. G. (1991). Multiple regression: Testing and interpreting interactions. Thousand Oaks, CA: Sage.

American Psychiatric Association. (1987). Diagnostic and statistical manual of mental disorders (3rd ed., rev.). Washington, DC: Author.

Beck, A. T., Steer, R., \& Garbin, M. (1988). Psychometric properties of the Beck Depression Inventory: Twenty-five years of evaluation. Clinical Psychology Review, 8, 77-100.

Beck, A. T., Ward, C. H., Mendelson, M. D., Mock, J., \& Erbaugh, J. (1961). An inventory for measuring depression. Archives of General Psychiatry, 4, 53-63.

Belin, T. R., Piacentini, J. C., Rotheram-Borus, M. J., \& Song, J. (1997). Handling missing items in a multivariate suicide prevention study (pp. 60-65). Proceedings of the American Statistical Association Biometrics Section, Alexandria, VA: American Statistical Association.

Bickman, L. (1996). A continuum of care: More is not always better. American Psychologist, 51, 689-701.

Bravo, M., Woodbury-Farina, M., Canino, G., \& Rubio-Stipec, M. (1993).
The Spanish translation and cultural adaptation of the Diagnostic Inter view Schedule for Children (DISC) in Puerto Rico. Culture, Medicine, \& Psychiatry, 17, 329-344.

Brent, D. A., Holder, D., Kolko, D., Birmaher, B., Baugher, M., Roth, C., Iyengar, S., \& Johnson, B. A. (1997). A clinical psychotherapy trial for adolescent depression comparing cognitive, family, and supportive therapy. Archives of General Psychiatry, 54, 877-885.

Centers for Disease Control and Prevention. (1998). Youth risk behavioral surveillance-United States, 1997. Morbidity and Mortality Weekly Report, 47(SS-3), 1-89.

Derogatis, L. R. (1974). The Hopkins Symptom Checklist (HSCL): A self-report symptom inventory. Behavioral Science, 19, 1-15.

Fisher, P. W., Shaffer, D., Piacentini, J., Lapkin, J., Kafantaris, V., Leonard, H., \& Herzog, D. B. (1993). Sensitivity of the Diagnostic Interview Schedule for Children, 2nd ed., (DISC-2.1) for specific diagnoses of children and adolescents. Journal of the American Academy of Child and Adolescent Psychiatry, 32, 666-673.

Hamilton, M. (1960). A rating scale for depression. Journal of Neurology, Neurosurgery, and Psychiatry, 26, 56-62.

Harkavy-Friedman, J. M., \& Asnis, G. (1989). Assessment of suicidal behavior: A new instrument. Psychiatric Annuals, 19, 382-387.

Harkavy-Friedman, J. M., Asnis, G. M., \& DiFiore, J. (1985). The Harkavy Asnis Suicide Scales. New York: Albert Einstein College of Medicine.

Harrington, R., Whittaker, J., \& Shoebridge, P. (1998). Psychological treatment of depression in children and adolescents: A review of treatment research. British Journal of Psychiatry, 173, 291-298.

Haynes, R. B. (1979). Introduction. In R. B. Haynes, D. W. Taylor, \& D. Sackett (Eds.), Compliance and Health Care (pp. 1-13). Baltimore: John Hopkins University Press.

Hazzard, A., Hutchinson, S. J., \& Krawiecki, N. (1990). Factors related to adherence to medication regimens in pediatric seizure patients. Journal of Pediatric Psychology, 15, 543-555.

Henggeler, S. W., Melton, G. B., Smith, L. A., Foster, S. L., Hanley, J. H., \& Hutchinson, C. M. (1993). Assessing violent offending in serious juvenile offenders. Journal of Abnormal Child Psychology, 21, 233-243.

Jensen, P., Roper, M., Fisher, P., Piacentini, J., Canino, G., Richters, J., Rubio-Stipec, M., Dulcan, M., Goodman, S., Davies, M., Rae, D., Shaffer, D., Bird, H., Lahey, B., \& Schwab-Stone, M. (1995). Test-retest reliability of the Diagnostic Interview Schedule for Children (version 2.1): Parent, child, and combined algorithms. Archives of General Psychiatry, 52, 61-71.

Laird, N. M., \& Ware, J. H. (1982). Random-effects models for longitudinal data. Biometrics, 38, 963-974.

Liu, M., Taylor, J. M. G., \& Belin, T. R. (1995). Multiple imputation and posterior simulation for multivariate missing data in longitudinal studies (pp. 142-147). Proceedings of the American Statistical Association Biometrics Section, Washington, DC: American Statistical Association.

Miller, S., Rotheram-Borus, M. J., Piacentini, J., \& Graae, F. (1992). Emergency Room Staff Training Manual for Adolescent Suicide Attempters. Los Angeles: Department of Psychiatry, University of California.

Miller, S., Rotheram-Borus, M. J., Piacentini, J., Graae, F., \& CastroBlanco, D. (1992). Successful Negotiation/Acting Positively (SNAP): A brief cognitive-behavioral family therapy manual for adolescent suicide attempters and their families. Los Angeles: Department of Psychiatry, University of California.

Murray, D. M. (1998). Design and analysis of group randomized trials. Oxford, England: Oxford University Press.

Olson, D. H. (1986). Circumplex model VII: Validation studies and FACES III. Family Process, 25, 337-351.

Olson, D. H., Portner, J., \& Lavee, Y. (1985). FACES III. St. Paul, MN: Family Social Science, University of Minnesota.

Pfeffer, C., Hurt, S., Kakuma, T., Peskin, J., Siefker, C. A., \& Nagabhairava, S. (1994). Suicidal children grow up: Suicidal episodes and effects of treatment during follow-up. Journal of the American Academy of Child and Adolescent Psychiatry, 33, 225-230. 
Piacentini, J. C., Cohen, P., \& Cohen, J. (1992). Combining discrepant diagnostic information from multiple sources: Are complex algorithms better than simple ones? Journal of Abnormal Child Psychology, 20, 51-63.

Piacentini, J., \& Fisher, P. (1993). The NIMH Diagnostic Interview Schedule for Children Scoring Logic (Version 2.3). New York: New York State Psychiatric Institute, Columbia University.

Piacentini, J., Rotheram-Borus, M. J., Gillis, J. R., Graae, F., Trautman, P., Garcia-Leeds, C., Cantwell, C., \& Shaffer, D. (1995). Demographic predictors of treatment attendance among adolescent suicide attempters. Journal of Consulting and Clinical Psychology, 63, 469-473.

Pierce, D. W. (1977). Suicidal intent in self-injury. British Journal of Psychiatry, 130, 377-385.

Prentice, R. L., \& Gloeckler, L. A. (1978). Regression analysis of grouped survival data with application to breast cancer data. Biometrics, 34, $57-67$.

Renaud, J., Brent, D. A., Baugher, M., Birmaher, B., Kolko, D. J., \& Bridge, J. (1998). Rapid response to psychosocial treatment for adolescent depression: A two-year follow-up. Journal of the American Academy of Child and Adolescent Psychiatry, 37, 1184-1190.

Ribera, J. C., Canino, G., Rubio-Stipec, M., Bravo, M., Bauermeister, J. J., Alegria, M., Woodbury, M., Huertos, S., Guevara, L. M., Bird, H. R., Freeman, D., \& Shrout, P. E. (1996). The Diagnostic Interview Schedule for Children (DISC-2.1) in Spanish: Reliability in a Hispanic population. Journal of Child Psychology \& Psychiatry \& Allied Disciplines, 37, 195-204.

Rodick, J. D., Henggeler, S. W., \& Hanson, C. L. (1986). An evaluation of the Family Adaptability and Cohesion and Evaluation Scales and the Circumplex model. Journal of Abnormal Child Psychology, 14, 77-87.

Rotheram-Borus, M. J. (1987). Evaluation of imminent danger for suicide among youth. American Journal of Orthopsychiatry, 57, 102-110.

Rotheram-Borus, M. J., Piacentini, J., Miller, S., Graae, F., \& CastroBlanco, D. (1994). Brief cognitive-behavioral treatment for adolescent suicide attempters and their families. Journal of the American Academy of Child and Adolescent Psychiatry, 33, 508-517.

Rotheram-Borus, M. J., Piacentini, J., Miller, S., Graae, F., Dunne, E., \& Cantwell, C. (1996). Toward improving treatment adherence among adolescent suicide attempters. Clinical Child Psychology and Psychiatry, 1, 99-108.

Rotheram-Borus, M. J., Piacentini, J., Van Rossem, R., Graae, F., Cantwell, C., Castro-Blanco, D., \& Feldman, J. (1996). Enhancing treatment adherence with a specialized emergency room program for adolescent suicide attempters. Journal of the American Academy of Child and Adolescent Psychiatry, 35, 654-663.

Rotheram-Borus, M. J., Piacentini, J., Van Rossem, R., Graae, F., Cantwell, C., Castro-Blanco, D., \& Feldman, J. (1999). Treatment adherence among Latina female adolescent suicide attempters. Suicide and Life Threatening Behaviors, 29(4), 319-331.

Rubin, D. B. (1987). Multiple imputation for nonresponse in surveys. New York: Wiley.

Rubio-Stipec, M., Shrout, P., Canino, G., Bird, H., Jensen, P., Dulcan, M.,
\& Schwab-Stone, M. (1996). Empirically defined symptom scales using the DISC 2.3, Journal of Abnormal Child Psychology, 24(1), 67-83.

Schafer, J. L. (1997). Analysis of incomplete multivariate data. New York: Chapman \& Hall.

Schafer, J. L. (1998). Imputation of missing covariates under a general linear mixed model. Technical report, Pennsylvania State University Department of Statistics.

Schwab-Stone, M., Fisher, P., Piacentini, J., Shaffer, D., Davies, M., \& Riggs, M. (1993). The Diagnostic Interview Schedule for Children (DISC-R): Test-retest reliability. Journal of the American Academy of Child and Adolescent Psychiatry, 32(3), 651-657.

Schwab-Stone, M., Shaffer, D., Dulcan, M., Jensen, P., Fisher, P., Bird, H., Goodman, S., Lahey, B., Lichtman, J., Canino, G., \& Regier, D. (1996). The NIMH Diagnostic Interview Schedule for Children (DISC-2): Description, acceptability, prevalences, and performance in the MECA study. Journal of the American Academy of Child and Adolescent Psychiatry, 35, 878-888.

Shaffer, D., Fisher, P., Dulcan, M., Davies, M., Piacentini, J., SchwabStone, M., Lahey, B., Bourdon, K., Jensen, P., Bird, H., Canino, I., \& Regier, D. (1996). The NIMH Diagnostic Interview Schedule for Children (DISC-2): Description, acceptability, prevalences, and performance in the MECA study. Journal of the American Academy of Child and Adolescent Psychiatry, 35, 865-877.

Shaffer, D., Fisher, P., Lucas, C., Dulcan, M., Schwab-Stone, M. (2000). NIMH Diagnostic Interview Schedule for Children IV (NIMH DISCIV): Description, differences from previous versions, and reliability of some common diagnoses. Journal of the American Academy of Child and Adolescent Psychiatry, 39(1), 28-38.

Shaffer, D., Fisher, P., Piacentini, J., Schwab-Stone, M., \& Wicks, J. (1989). The NIMH Diagnostic Interview Schedule for Children (DISC2). New York: New York State Psychiatric Institute, Columbia University.

Shaffer, D., \& Piacentini, J. (1994). Suicide and suicide attempts. In M. Rutter, L. Hersov, \& E. Taylor (Eds.), Child and adolescent psychiatry (3rd ed., pp. 407-424). London: Blackwell Scientific.

Spirito, A., Brown, L., Overholser, J., \& Fritz, G. (1989). Attempted suicide in adolescence: A review and critique of the literature. Clinical Psychology Review, 9, 335-363.

Taylor, S. E., Wayment, H. A., \& Collins, M. A. (1993). Positive illusions and affect regulation. In M. Daniel, E. Wegner, \& J. W. Pennebaker (Eds.), Handbook of mental control (pp. 325-343). Englewood Cliffs, NJ: Prentice Hall.

Trautman, P. D., Stewart, N., \& Morishima, A. (1993). Are adolescent suicide attempters noncompliant with outpatient care? Journal of the American Academy of Child and Adolescent Psychiatry, 32, 89-94.

Received May 10, 1999

Revision received December 7, 1999 Accepted April 18, 2000 